\title{
Effects of diet, energy restriction and diabetes on hexose transport in the rat
}

\author{
BY HELEN D. WILSON AND H. P. SCHEDL \\ Gastroenterology Research Laboratories, \\ Department of Medicine, University of Iowa College of Medicine, \\ Iowa City, Iowa 52242, USA
}

(Received 6 February 1978 - Accepted 16 October 1978)

\begin{abstract}
I. Effects of dietary composition, energy restriction, and diabetes on hexose absorption were examined by feeding male rats isoenergetic, semi-synthetic diets of differing carbohydrate and protein content. Diets were carbohydrate, $(\mathrm{g} / \mathrm{kg}): 890$ sucrose; carbohydrate-protein, 500 sucrose, 390 casein; or protein, 890 casein. An additional group was fed on commercial rat chow ad lib.

2. Hexose (3-O-methyl-D-glucose) absorption was measured by luminal perfusion of the entire small intestine in situ. Absorption by the total small intestine, i.e. absorption per rat, and absorption per $g$ dry weight of mucosa (specific absorption) were calculated.

3. When semi-synthetic diets were fed at $210 \mathrm{~kJ} / \mathrm{d}$ to normal animals absorption depended on composition of diets: carbohydrate enhanced or protein suppressed hexose absorption. Dietary carbohydrate as glucose, dextrimaltose or starch gave the same hexose absorption response as sucrose.

4. When diets of normal rats were restricted to $118 \mathrm{~kJ} / \mathrm{d}$, specific absorption was independent of dietary composition and was increased for all dietary groups to the level of the group fed on the carbohydrate diet at $210 \mathrm{~kJ} / \mathrm{d}$.

5. When diabetic rats were given $210 \mathrm{~kJ} / \mathrm{d}$, hexose specific absorption was the same for all diabetic groups independent of dietary composition and was equal to that of controls given carbohydrate, but greater than that of protein-fed controls.

6. Thus, when two of the three stimuli (i.e. carbohydrate diet plus energy restriction or diabetes) were combined, the effect was not additive, and the response of hexose specific absorption to diabetes and energy restriction was the same: absorption was independent of dietary composition and was stimulated relative to controls fed on diets containing protein.

7. The pattern of response of total small intestinal hexose absorption to the stinuli of dietary composition, energy restriction and diabetes was similar to that of specific absorption.

8. Compared with groups given semi-synthetic diets, rats eating commercial rat chow ad lib. (approximately $286 \mathrm{~kJ} / \mathrm{d}$ ) showed increased mucosal mass and decreased specific absorption, but total absorption was similar to that of the carbohydrate and carbohydrate-protein-fed groups.

9. In a separate study in control rats, specific and total intestinal absorption of $L$-leucine did not respond to dietary composition, i.e. level of protein fed.
\end{abstract}

Hexose absorption in the small intestine responds to both exogenous influences, such as composition and energy intake of diet, and endogenous factors such as diabetes. In the rat restriction of energy (Esposito, 1967; Kershaw et al. 1960; Levinson \& Englert, 1972; Sanford \& Smyth, 1974) and experimental diabetes (Olsen \& Rosenberg, 1970; Schedl \& Wilson, I97 $(a)$ enhance hexose absorption. However, energy restriction (Levin et al. 1965; Levin, 1970) has also been reported to reduce hexose absorption. Carbohydrate absorption may be influenced by type of carbohydrate fed (Reiser et al. 1975) and by dietary carbohydrate and protein content (Lifshitz et al. 1972). It is not known whether single or multiple mechanisms are involved in effects of these stimuli on hexose absorption. Examination of intestinal hexose absorption in response to these stimuli applied singly and in combination might establish whether one or more mechanisms are involved. For example, an additive effect from application of two stimuli would suggest separate mechanisms for the individual stimuli. Alternatively, if application of a second stimulus produced no additional response to hexose absorption, a common mechanism of enhancement is 
implied. We examined singly and in combination the hexose absorptive responses to dietary carbohydrate and protein, energy restriction, and diabetes and report our findings.

\section{METHODS}

Male albino Sprague-Dawley rats, 45-55 d old, obtained from Simonsen Labs, Gilroy, California, were housed individually in metabolic cages in a separate room in the Animal Care Unit. All feeding, weighing and sample collections were carried out by investigators involved in the experiment. A dark period from 18.00 to 06.00 hours was controlled automatically. Ground Teklad ( $40 \mathrm{~g}$ fat $/ \mathrm{kg}$ rat $/$ mouse diet (Teklad Mills, Madison, Wisconsin)) was fed $a d$ lib. for $2 \mathrm{~d}$ after housing rats in metabolic cages to adapt animals to isolation and ground food. Food was given at 09.00 hours each day. Semi-synthetic diets varying in carbohydrate and protein content were prepared. These were a high carbohydrate diet of $890 \mathrm{~g}$ sucrose (powdered Fisher certified; Fisher Chemical $\mathrm{Co}$ ) $/ \mathrm{kg}$ (CHO), a mixed carbohydrate-protein diet of $500 \mathrm{~g}$ sucrose and $390 \mathrm{~g}$ casein (vitamin-free, certified; Fisher Chemical Co)/kg (CHO-PRO), and a carbohydrate-free high-protein diet of $890 \mathrm{~g}$ casein $/ \mathrm{kg}$ (PRO). Each diet contained $(\mathrm{g} / \mathrm{kg}) 50$ fat as maize oil, 40 Bernhart-Tomarellimodified mineral mix (Bernhart \& Tomarelli, I966), 20 vitamin fortification mix (Nutritional Biochemical Co, Cleveland, Ohio). By limiting food intake to $12.5 \mathrm{~g}$ or $210 \mathrm{~kJ} / \mathrm{d}$, rats in all dietary groups could be pair-fed. Preliminary feeding trials established this to be the maximum level of intake of the CHO and PRO diets.

A separate control group, housed in metabolic cages so that food intake could be measured, was given a normal diet ad lib. (Teklad Commerical Rat Chow containing $(\mathrm{g} / \mathrm{kg}): 259$ protein, 437 carbohydrate, $40 \mathrm{fat} ; 1 \mathrm{I} \cdot 93 \mathrm{~kJ} / \mathrm{g})$. Mean intake by this group was $286 \mathrm{~kJ} / \mathrm{d}$.

In all experiments, shipments of rats were divided randomly for assignment to diets and groups. In Expt A, rats were fed on semi-synthetic diets for 6-8 d, $210 \mathrm{~kJ} / \mathrm{d}$, or Teklad $286 \mathrm{~kJ} / \mathrm{d}$ before the absorption studies. The energy-restricted group received II $8 \mathrm{~kJ} / \mathrm{d}$ for each diet. Values from all rats given $210 \mathrm{~kJ} / \mathrm{d}$ were pooled by diet and compared with the energy-restricted groups by a two-way analysis of variance followed by Tukey's multiple comparison test (Huntsberger \& Leaverton, I970), with the type of diet being one factor and the energy level being the second factor.

Expt B evaluated the hexose absorptive response to four forms of carbohydrate. Four groups of rats were fed on the $890 \mathrm{~g}$ carbohydrate $/ \mathrm{kg}$ semi-synthetic diet with the carbohydrate as sucrose, glucose (Fisher certified; Fisher Chemical Co), dextrimaltose (Mead Johnson Laboratories, Evansville, Indiana) or starch (Fisher certified; Fisher Chemical Co). Absorption was measured as in Expt A after 6-8 d of pair-feeding $210 \mathrm{~kJ} / \mathrm{d}$.

In Expt $\mathrm{C}$, diabetes was induced in one group given Teklad by intraperitoneal injection of $100 \mathrm{mg}$ streptozotocin (supplied by the Upjohn Co, Kalamazoo, Michigan) $/ \mathrm{kg}$ in citrate buffer, $\mathrm{pH} 4.5$, with a second injection of $25 \mathrm{mg} / \mathrm{kg}$ on the next day. The control group was injected with buffer only. On the afternoon of the second injection, rats were evaluated for diabetes by glucosuria greater than $2 \%$ (TesTape; Eli Lilly \& Co, Indianapolis, Indiana) and weight loss. Diabetic rats and corresponding controls were then given one of the three semi-synthetic diets for 2-3d. Absorption was studied at 3-4 d after initial injection, when intestinal growth is similar in controls and diabetics (Schedl \& Wilson, I971 $b$ ).

Hexose absorption was tested by perfusing 3-O-methyl-D-glucose (3-O-MG) through the entire small intestine at a rate of $\mathrm{I} \cdot 0 \mathrm{ml} / \mathrm{min}$ and measured as the disappearance from the initial solution after correction for water movement as previously described (Schedl \& Wilson, I97 $1 a$ ). Rats were not fasted before perfusion. A 30 min equilibration period was 
followed by four $15 \mathrm{~min}$ collections. At the end of perfusion, the small intestine was removed, the contents expressed onto absorbent paper, and length and full thickness wet weight of intestine measured. Wet and dry weights of mucosa and underlying tissue were obtained by scraping the mucosa with a glass microscope slide after slitting the gut lengthwise on a glass plate. Tissues were dried at $100^{\circ}$ in a vacuum oven for $24 \mathrm{~h}$. For diabetic and corresponding control animals, blood was obtained from the tail vein before perfusion for blood glucose analysis (Somogyi, 1952).

Expt $\mathrm{D}$ evaluated L-leucine absorption in control animals given the three semi-synthetic diets at $210 \mathrm{~kJ} / \mathrm{d}$ as described for Expt A. L-Leucine was perfused at $3.0 \mathrm{ml} / \mathrm{min}$ as described for hexose absorption.

Solutions. The perfusion solution for hexose absorption contained $56 \mathrm{~mm}-(3-O-\mathrm{MG})$ (Sigma Chemical Co) and 3-O- ${ }^{14} \mathrm{C}$-methyl-D-glucose (specific activity $50 \mu \mathrm{Ci} / \mu \mathrm{mol}, \mathrm{I} 2 \mu \mathrm{Ci} / \mathrm{l}$; New England Nuclear) in 125 mM-sodium chloride with phenol red as non-absorbed indicator. The $5 \mathrm{~mm}$-L-leucine solution (Fisher Chemical $\mathrm{Co}$ ) contained ${ }^{14} \mathrm{C}$-L-leucine (uniformly-labelled, $250 \mu \mathrm{Ci} / \mu \mathrm{mol}, \mathrm{I} 2 \mu \mathrm{Ci} / 1$; New England Nuclear) in I $50 \mathrm{~mm}-\mathrm{NaCl}$ with phenol red. Radioactivity was measured by liquid-scintillation counting (Beckman LS 250) in the initial perfusate and in each of the four 15 min collections, using $0.5 \mathrm{ml}$ solution, $0.5 \mathrm{ml}$ water and $10 \mathrm{ml}$ modified Bray's solution (Bray, 1960).

Phenol red concentration was analysed spectrophotometrically (Schedl \& Clifton, I961), and absorption of $3-O-\mathrm{MG}$ was expressed as total amount absorbed (mmol) per small intestine per $\mathrm{h}$ (total absorption per rat) or $\mathrm{mmol} / \mathrm{g}$ dry weight of mucosa per $\mathrm{h}$ (specific absorption). In L-leucine studies absorption is expressed as mmol/intestinal unit. Absorption was calculated as previously described (Schedl et al. 1969).

Results from control and diabetic rats were compared by a three-way analysis of variance and Tukey's multiple comparison test (Huntsberger \& Leaverton, 1970) (the type of diet being one factor, the diabetic or control state being the second factor, and the shipment being the third factor).

\section{RESULTS}

In all experiments the groups of animals compared were closely matched for initial weight as illustrated by values for groups in Expt A fed on commercial laboratory chow ad lib. or the three semi-synthetic diets at 210 and $1 \mathrm{r} 8 \mathrm{~kJ} / \mathrm{d}$ (Fig. I). Animals fed at $2 \mathrm{IO} \mathrm{kJ} / \mathrm{d}$ maintained or increased their body-weight if given diets containing protein (PRO, CHOPRO), but lost weight when given the carbohydrate ( $\mathrm{CHO}$ ) diet. Rats eating commercial laboratory chow, $286 \mathrm{~kJ} / \mathrm{d}$, gained weight over the $6-8 \mathrm{~d}$ period. When diets were restricted to $118 \mathrm{~kJ} / \mathrm{d}$ (Fig. I) all dietary groups lost weight. Diabetics also lost weight independent of the diet fed (results not shown).

Expt $A$. The response in dry weight of the mucosa to dietary composition and energy restriction is shown in Fig. 2. The dry weight of the mucosa was decreased by feeding CHO at $210 \mathrm{~kJ} / \mathrm{d}$ as compared with feeding PRO and CHO-PRO diets. The dry weight of mucosa from rats eating natural food $a d$ lib. was 1.4 times that of rats eating CHO-PRO, $210 \mathrm{~kJ} / \mathrm{d}$. When diets were fed at $118 \mathrm{~kJ} / \mathrm{d}$, dietary composition had no effect on the dry weight of mucosa, which was lower in energy-restricted groups given PRO and CHOPRO than when these diets were fed at $210 \mathrm{~kJ} / \mathrm{d}$. For the CHO diet, the dry weight of the mucosa was the same for groups receiving both 210 and $118 \mathrm{~kJ} / \mathrm{d}$.

Hexose specific absorption (mmol/g dry weight mucosa per $h$ ) depended on the composition of diets when fed at $210 \mathrm{~kJ} / \mathrm{d}$ (Fig. 3). Absorption by the PRO group was lower than that by the CHO-PRO and CHO groups. Hexose specific absorption was independent of dietary composition when diets were fed at II $8 \mathrm{~kJ} / \mathrm{d}$. Energy restriction increased specific absorption for groups given PRO and CHO-PRO as compared with the groups 


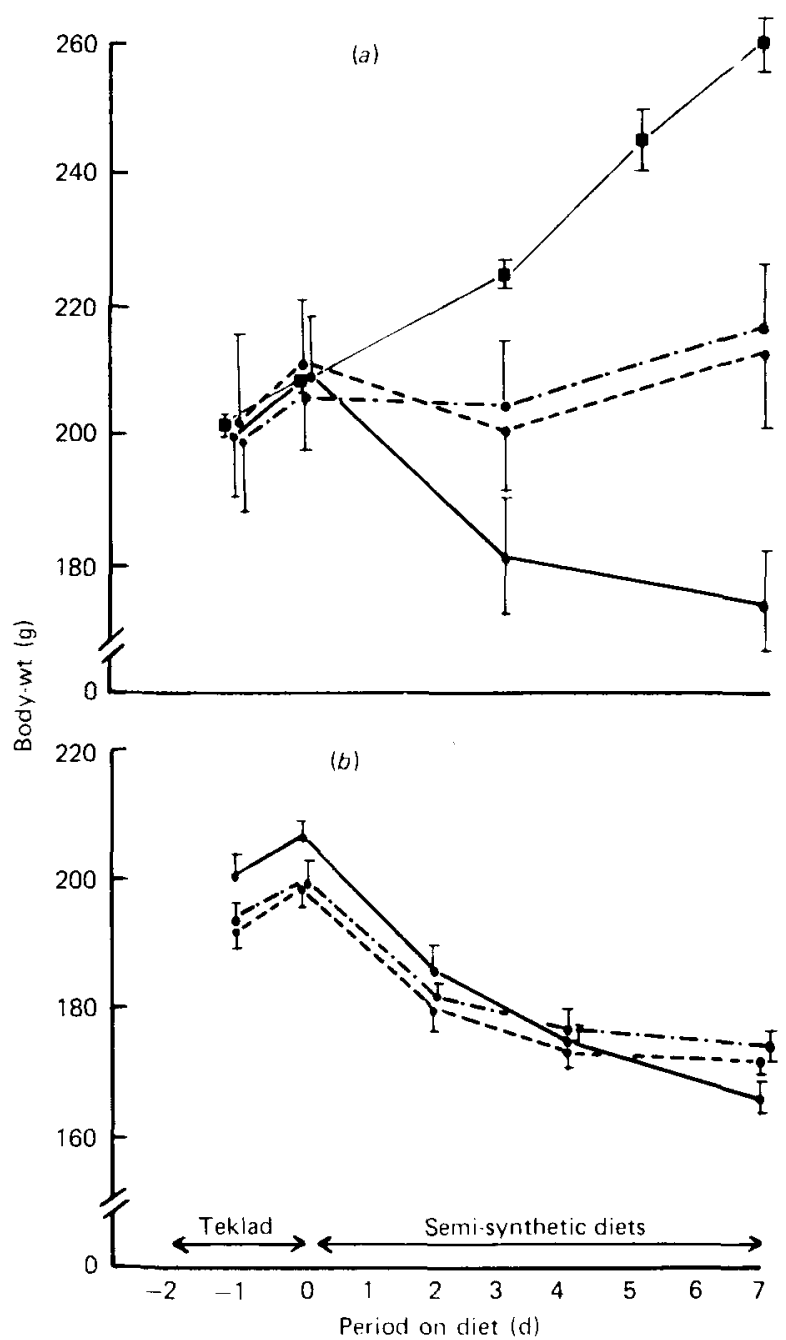

Fig. I. Expt A. Effects of dietary composition and energy restriction on body-weight gain (g) of rats fed the diets for $6-8 \mathrm{~d}$. The diets were $(\mathrm{g} / \mathrm{kg})$ : $\mathbf{n}-\mathbf{n}$, commerical rat chow (440 carbohydrate, 260 protein) and the following semi-synthetic diets; - -890 sucrose (CHO); - -1 500 sucrose-390 casein (CHO-PRO); - -, 890 casein (PRO). Diets were fed at (a) commercial rat chow, $286 \mathrm{~kJ} / \mathrm{d}$ and semi-synthetic diets $210 \mathrm{~kJ} / \mathrm{d}$; $(b)$ semi-synthetic diets, $118 \mathrm{~kJ} / \mathrm{d}$. Points represent mean values, with their standard errors represented by vertical bars. Values are shown only for selected days to represent the pattern of daily measurements. No. of animals/ group were: commerical rat chow 11 , semi-synthetic diets: $210 \mathrm{~kJ} / \mathrm{d}, \mathrm{CHO} 7, \mathrm{CHO}-\mathrm{PRO} 6, \mathrm{PRO} 7$; $118 \mathrm{~kJ} / \mathrm{d}, \mathrm{CHO} 6, \mathrm{CHO}-\mathrm{PRO} 7, \mathrm{PRO} 8$.

receiving $210 \mathrm{~kJ} / \mathrm{d}$, but specific absorption was similar at both energy intake levels for groups receiving $\mathrm{CHO}$. When normal rats were fed on commerical rat chow ad lib. specific absorption was $22 \%$ lower than that of rats receiving CHO-PRO semi-synthetic diet, $210 \mathrm{~kJ} / \mathrm{d}$.

Expt $B$. Feeding the CHO diet as glucose, dextrimaltose or starch had the same effect on values for specific absorption and total absorption as feeding sucrose (Table I). Mucosal dry weights did not differ among groups. 


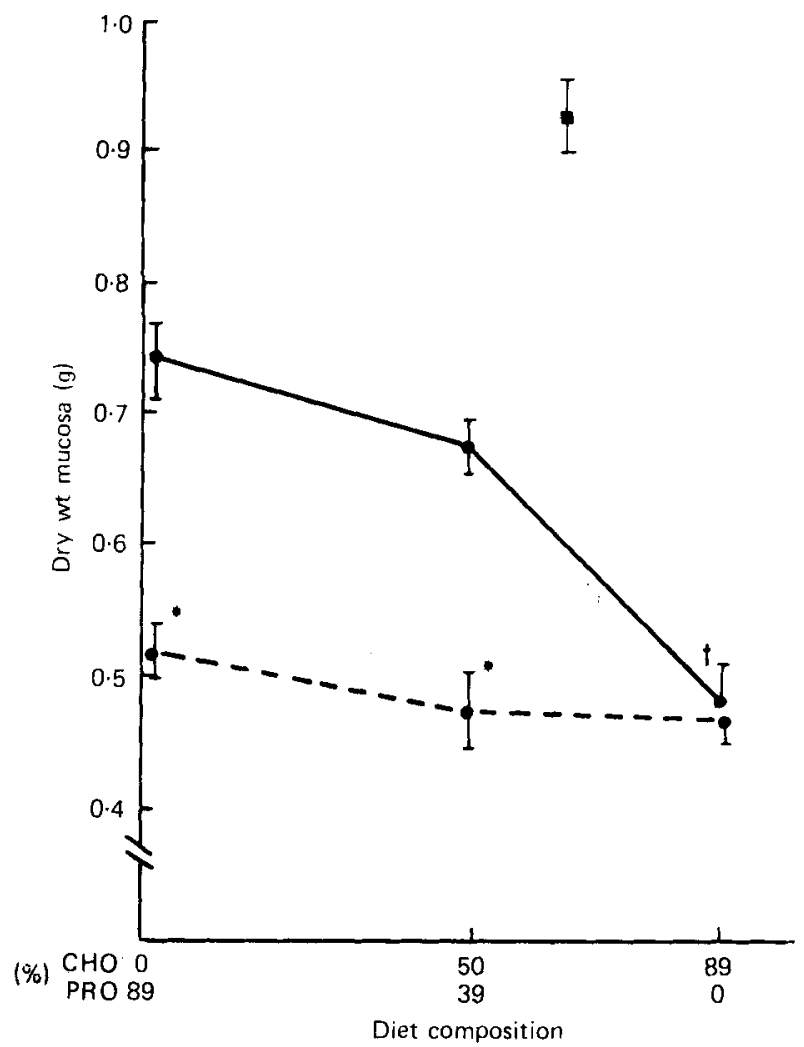

Fig. 2. Expt A. Effects of dietary composition and energy restriction on dry weight of mucosa (g) of rats given the diets for $6-8 \mathrm{~d}$. The diets were $(\mathrm{g} / \mathrm{kg}$ ): commercial rat chow (440 carbohydrate, 260 protein) and the following semi-synthetic diets: 890 sucrose (CHO); 500 sucrose390 casein (CHO-PRO); 890 casein (PRO). Commercial rat chow was given at $286 \mathrm{~kJ} / \mathrm{d}$ (Ш), semi-synthetic diets at $210 \mathrm{~kJ} / \mathrm{d}(-)$ ) and $118 \mathrm{~kJ} / \mathrm{d}(--)$. No. of animals/group were: commerical rat chow 1 I, semi-synthetic diets: $210 \mathrm{~kJ} / \mathrm{d}$, CHO 7, CHO-PRO 6, PRO $7 ;$ i $18 \mathrm{~kJ} / \mathrm{d}$, CHO 6, CHO-PRO 7, PRO 8. Points represent mean values with their standard errors represented by vertical bars. ${ }^{*} 118 \mathrm{~kJ} /$ day groups $<210 \mathrm{~kJ} / \mathrm{d}$ for diet PRO and CHO-PRO $(P<0.05)$; $\dagger \operatorname{diet} \mathrm{CHO}<\operatorname{diet}$ PRO and CHO-PRO at $210 \mathrm{~kJ} / \mathrm{d}(P<0.05)$.

Expt C. Mucosal dry weight was independent of diabetes and the composition of diets fed at $210 \mathrm{~kJ} / \mathrm{d}$ for $2-3 \mathrm{~d}$ (Fig. 4). Hexose specific absorption (Fig. 5) of control groups depended on the composition of the diet and was greater for groups fed $\mathrm{CHO}$ and $\mathrm{CHO}-$ PRO than for the group fed PRO. Specific absorption of diabetics was independent of diet and was greater in diabetics than in controls when the diet was PRO.

Total intestinal hexose absorption or absorption per rat for studies $\mathrm{A}$ and $\mathrm{C}$ is shown in Fig. 6. When the intake was $210 \mathrm{~kJ} / \mathrm{d}$, total absorption was lower in the PRO than the CHO-PRO group; when energy was restricted, total absorption was the same for all dietary groups. Energy restriction increased total hexose absorption for the PRO group but had no effect when the other two diets were fed. Normal rats receiving commercial rat chow ad lib. absorbed similar amounts of $3-O-\mathrm{MG}$ per total intestine as rats eating the CHO-PRO and CHO semi-synthetic diets at $210 \mathrm{~kJ} / \mathrm{d}$.

The effects of diet and diabetes (Expt $\mathrm{C}$ ) on total intestinal hexose absorption are shown in Fig. 6. Absorption in controls given CHO-PRO and $\mathrm{CHO}$ was greater than that in 


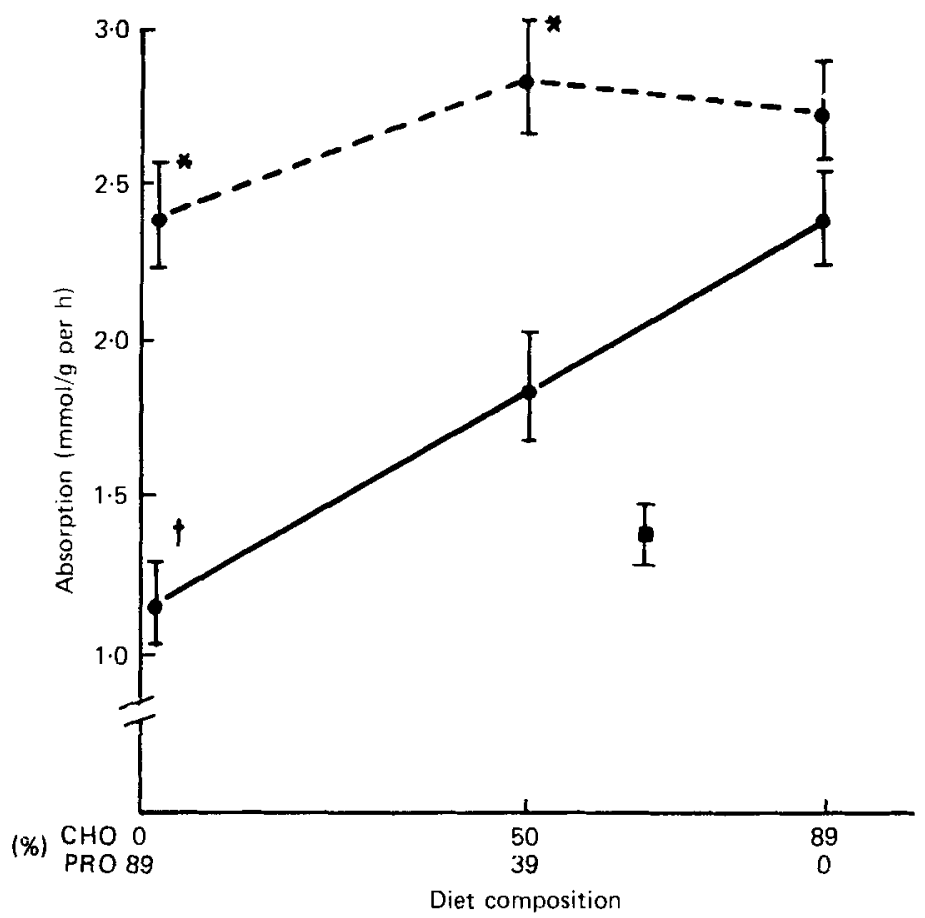

Fig. 3. Expt A. Effects of dietary composition and energy restriction on hexose specific absorption of rats given the diets for $6-8 \mathrm{~d}$. The diets were $(\mathrm{g} / \mathrm{kg})$ : commerical rat chow ( 440 carbohydrate, 260 protein) and the following semi-synthetic diets: 890 sucrose (CHO); 500 sucrose-390 casein (CHO-PRO); 890 casein (PRO). Commerical rat chow was given at $286 \mathrm{~kJ} / \mathrm{d}(\mathbf{\square})$, semi-synthetic diets at $210 \mathrm{~kJ} / \mathrm{d}(-\infty)$ and $118 \mathrm{~kJ} / \mathrm{d}(-$.$) ). No. of animals/group were: commerical rat$ chow I I, semi-synthetic diets: $210 \mathrm{~kJ} / \mathrm{d}, \mathrm{CHO} 7, \mathrm{CHO}-\mathrm{PRO} 6, \mathrm{PRO} 7 ; \mathrm{I} / 8 \mathrm{~kJ} / \mathrm{d}, \mathrm{CHO} 7, \mathrm{CHO}-$ PRO 7, PRO 8. Points represent mean values with their standard errors represented by vertical bars. * II $8 \mathrm{~kJ} / \mathrm{d}$ groups $>210 \mathrm{~kJ} / \mathrm{d}$ for diet PRO or CHO-PRO $(P<0.05)$; $\dagger$ diet PRO $<$ diet $\mathrm{CHO}$ at $210 \mathrm{~kJ} / \mathrm{d}(P<0.05)$.

Table I. Expt B. Effects of form of carbohydrate (CHO) fed at $890 \mathrm{~g} / \mathrm{kg}$ diet on mucosal dry weight $(\mathrm{g})$ and hexose absorption $(\mathrm{mmol} / \mathrm{h})$

(Mean values with their standard errors; no. of animals in parentheses)

\begin{tabular}{|c|c|c|c|c|c|c|}
\hline \multirow[b]{3}{*}{$\mathrm{CHO}$} & & & \multicolumn{4}{|c|}{ Absorption } \\
\hline & \multicolumn{2}{|c|}{ Mucosal dry wt } & \multicolumn{2}{|c|}{ Per g dry wt mucosa } & \multicolumn{2}{|c|}{ Per total intestine } \\
\hline & Mean & SE & Mean & SE & Mean & SE \\
\hline Sucrose & 0.479 & 0.020 & $2 \cdot 43$ & 0.12 & $I \cdot 15$ & 0.05 \\
\hline Glucose & 0.479 & 0.015 & $2 \cdot 15$ & 0.14 & $1 \cdot 02$ & 0.05 \\
\hline Dextrimaltose (7) & 0.512 & 0.012 & $2 \cdot 19$ & 0.18 & $I \cdot I 2$ & 0.08 \\
\hline Starch & 0.557 & 0.029 & $2 \cdot 25$ & 0.13 & $I \cdot 25$ & 0.09 \\
\hline
\end{tabular}

controls given PRO. In diabetics total hexose absorption was independent of diet and was greater in diabetics than in controls when the diet was PRO.

Expt D. L-Leucine absorption when expressed per $\mathrm{g}$ dry weight of mucosa and per total intestine was independent of dietary composition (Table 2). The dry weight of mucosa of the PRO group was greater than for the CHO group. 


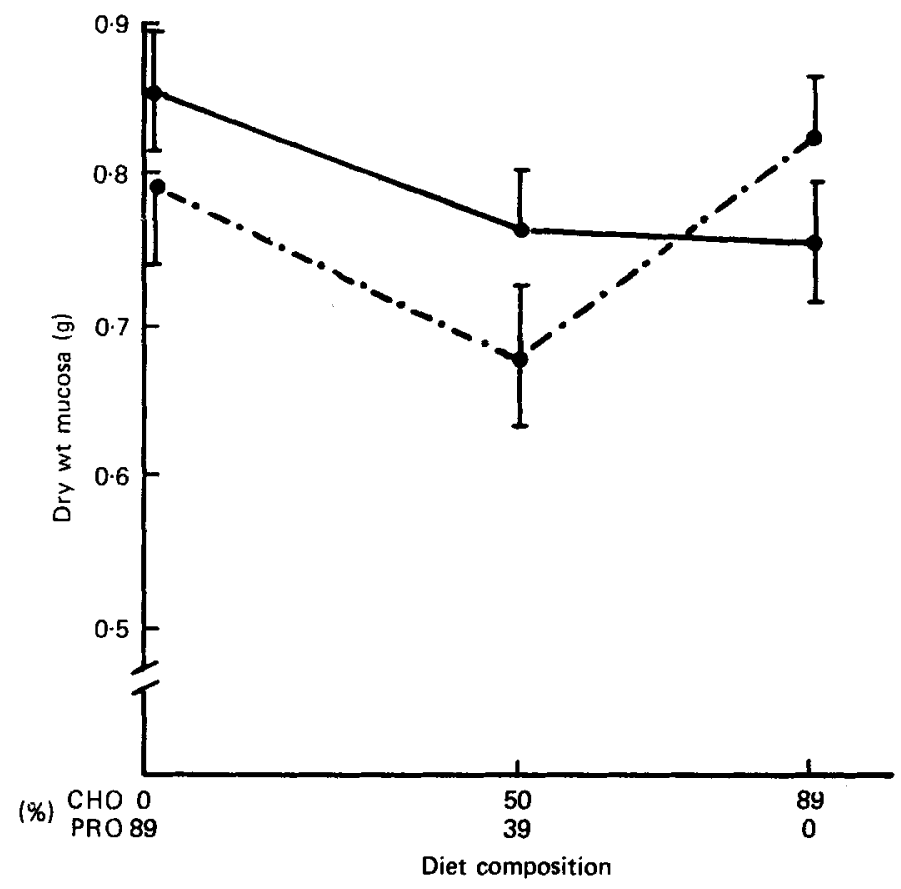

Fig. 4. Expt C. Effects of dietary composition and diabetes on dry weight of mucosa (g) of (-) control and $(-\rightarrow)$ diabetic rats given the diets for $2-3 \mathrm{~d}$ at $210 \mathrm{~kJ} / \mathrm{d}$. The diets were $(\mathrm{g} / \mathrm{kg})$ : 890 sucrose (CHO); 500 sucrose-390 casein (CHO-PRO); 890 casein (PRO). Points represent mean values with their standard errors represented by vertical bars. No. of animals/group were: controls, CHO 9, CHO-PRO I I, PRO I i d diabetics, CHO 8, CHO-PRO 6, PRO 9. Mucosal dry weights are the same for all groups.

Because the individual stimuli and combinations of stimuli caused greatly differing effects on body-weight, total absorption per $\mathrm{g}$ body-weight was evaluated for all groups, to derive an index of significance of the adaptive processes to homoeostasis of the organism. The pattern was similar to that of total absorption (Fig. 6). No combination of stimuli coupled with weight loss caused a greater response than that achieved when body-weight was not considered.

\section{DISCUSSION}

The response of hexose absorption in the small intestine to several stimuli was examined by perfusing the entire small intestine of the rat with the non-metabolized glucose analogue 3-O-MG. Studies were designed to use the stimulus of dietary composition (carbohydrate and protein content). Since the form of carbohydrate fed might alter the hexose absorption response, diets containing mono-, di- and polysaccharides were compared. Additional stimuli of energy restriction and diabetes were applied to examine effects of concurrent stimuli. Absorption of $3-O-M G$ in normal rats receiving commerical rat chow ad lib. is a reference point for the normal rats receiving semi-synthetic diets varying in levels of carbohydrate and protein. Finally, since the response of hexose absorption was to increase with carbohydrate and to decrease with protein content of diets, L-leucine absorption was examined to determine whether absorption of an amino acid responded reciprocally.

To examine the response of hexose absorption to the amount and form of dietary carbohydrate the carbohydrate effect was maximized by feeding $\mathrm{CHO}$ ( $890 \mathrm{~g}$ sucrose $/ \mathrm{kg}$ 


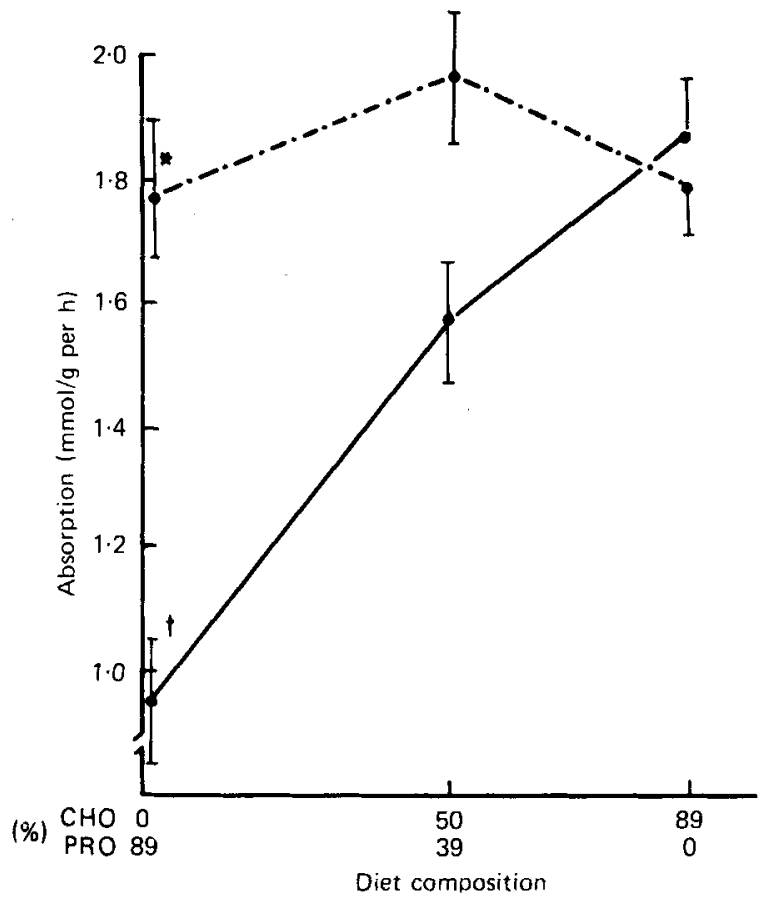

Fig. 5. Expt B. Effect of dietary composition and diabetes on specific hexose absorption of $(-)$ control and (-.-) diabetic rats given the diets for $2-3 \mathrm{~d}$ at $210 \mathrm{~kJ} / \mathrm{d}$. The diets were $(\mathrm{g} / \mathrm{kg})$ : 890 sucrose (CHO); 500 sucrose-390 casein (CHO-PRO); 890 casein (PRO). Points represent mean values with their standard errors represented by vertical bars. No. of animals/group were: controls, CHO 9, CHO-PRO I I, PRO I I ; diabetics, CHO 8, CHO-PRO 6, PRO 9. * Diabetic group $>$ controls for diet PRO $(P<0.05)$; $\dagger$ diet PRO $<\operatorname{diet~CHO-PRO~and~CHO~for~controls.~}$

as the carbohydrate). Diet PRO in which the carbohydrate was replaced by the protein, casein, was fed to minimize carbohydrate effect, and CHO-PRO a mixed carbohydrate-protein diet $(500 \mathrm{~g}$ sucrose, $390 \mathrm{~g}$ casein $/ \mathrm{kg}$ ) was fed to examine the effects of a balanced diet. In Expt $\mathrm{A}$ effects of these diets pair-fed at the maximum amount the animals would eat $(210 \mathrm{~kJ} / \mathrm{d})$ were compared among diets and with energy restriction of the diets $(118 \mathrm{~kJ} / \mathrm{d})$. Diets were fed for 6-8 $d$ to determine the magnitude of a well established response, while minimizing deterioration of animals by prolonged feeding of unbalanced diets. Bodyweight decreased for the first 2-3 d on the diets, then reached a plateau or increased suggesting metabolic adjustment (Fig. I). In Expt B the effects of feeding different forms of carbohydrate (glucose, sucrose, dextrimaltose or starch) for 6-8 d were compared; in Expt $\mathrm{C}$ the three diets' were fed for $2-3 \mathrm{~d}$.

When diet composition was used as the only stimulus in control animals specific absorption of hexose (per $g$ dry weight of mucosa) and total absorption tended to be proportional to the carbohydrate content of diet. The response of total intestinal hexose absorption is more difficult to interpret than that of specific absorption, since it involves responses of both specific absorption and mucosal mass. Mucosal mass was greater in the PRO group $(210 \mathrm{~kJ} / \mathrm{d}$ ) when animals were fed for 6-8 d (Fig. 2). Nevertheless, total absorption was lower in this group (Fig. 6), suggesting that specific absorption is a more important determinant of total absorption than the amount of mucosa. Compared with rats given semi-synthetic diets, normal rats receiving commerical chow ad lib. had increased 


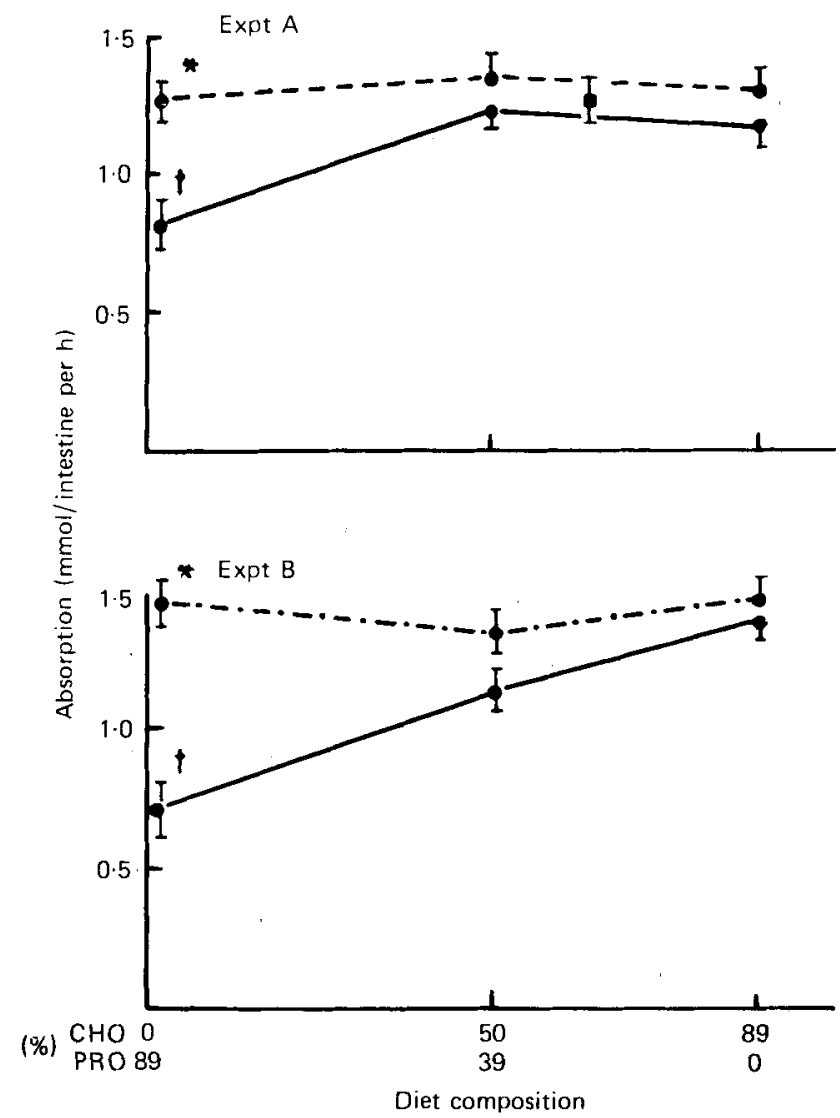

Fig. 6. Total hexose absorption. Effect of dietary composition and energy intake (Expt A) and effects of dietary composition and diabetes (Expt C). Commerical rat chow ( $\boldsymbol{\omega}$ ) was given at $286 \mathrm{~kJ} / \mathrm{d}$ and semi-synthetic diets at $210 \mathrm{~kJ} / \mathrm{d} \mathrm{(-)}$ ) and $118 \mathrm{~kJ} / \mathrm{d} \mathrm{(--)}$ in Expt A. Controls (and diabetics $(--$ ) were given semi-synthetic diets at $210 \mathrm{~kJ} / \mathrm{d}$ in Expt C. The diets were $(\mathrm{g} / \mathrm{kg})$ : commercial rat chow (440 carbohydrate, 260 protein) and the following semi-synthetic diets: 890 sucrose (CHO); 500 sucrose-390 casein (CHO-PRO); 890 casein (PRO). Points represent mean values with their standard errors represented by vertical bars. No. of animals/group were: commercial rat chow $\mathrm{I}$, semi-synthetic diets: $210 \mathrm{~kJ} / \mathrm{d}, \mathrm{CHO} 7, \mathrm{CHO}-\mathrm{PRO} 6, \mathrm{PRO} 7 ;$ I $8 \mathrm{~kJ} / \mathrm{d}$, CHO 6, CHO-PRO 7, PRO 8; diabetics, CHO 8, CHO-PRO 6, PRO 9; controls, CHO 9, CHOPRO II, PRO II. Expt A: ${ }^{*} 118 \mathrm{~kJ} / \mathrm{d}$ group $>210 \mathrm{~kJ} / \mathrm{d}$ for diet PRO $(P<0.05)$; $\dagger$ diet PRO < diet CHO-PRO at $210 \mathrm{~kJ} / \mathrm{d}(P<0.05)$. Expt $\mathrm{C}:{ }^{*}$ diabetics $>$ controls for diet PRO $(P<0.05)$; $\dagger$ diet PRO $<$ diet CHO-PRO and CHO for controls $(P<0.05)$.

mucosal weight with decreased specific absorption, but total absorption was similar to that of the CHO-PRO and CHO diet groups. When diets were fed for $2-3 \mathrm{~d}$ and mucosal mass did not differ among dietary groups (Fig. 4), specific absorption (Fig. 5) also determined total absorption (Fig. 6). Total absorption is an index for assessing benefit derived by the organism from the adaptive response.

Previous studies of effects of dietary composition on hexose absorption have defined no 'clear-cut' effect. When semi-synthetic diets were compared (low protein, $40 \mathrm{~g}$ casein, 450 or $700 \mathrm{~g}$ glucose $/ \mathrm{kg}$; normal protein, $\mathrm{I} 80 \mathrm{~g}$ casein, 450 or $700 \mathrm{~g}$ glucose $/ \mathrm{kg}$ ), glucose absorption per unit length of jejunum was increased in groups receiving the low-protein diets, 
Table 2. Expt D. Effect of composition of diets fed at $210 \mathrm{~kJ} / \mathrm{d}$ for $6-8 \mathrm{~d}$ on mucosal dry weight $(\mathrm{g})$ and L-leucine absorption $(\mathrm{mmol} / \mathrm{g})$

(Mean values with their standard errors)

Diet $\ldots$
No. of animals $\ldots$

Mucosal dry wt
Absorption
Per g dry wt mucosa
Per total intestine

$\overbrace{\text { Mean }}^{2} \begin{array}{cc}\text { PRO } \\ 0.685 & 0.025^{*} \\ 0.434 & 0.029 \\ 0.296 & 0.018\end{array}$

$\overbrace{\text { Mean }}^{2}$\begin{tabular}{ll}
\multicolumn{2}{c}{ CHO-PRO } \\
0.632 & 0.016 \\
0.471 & 0.034 \\
0.298 & 0.021
\end{tabular}

\begin{tabular}{|c|c|}
\hline \multicolumn{2}{|c|}{$\begin{array}{c}\mathrm{CHO} \\
5\end{array}$} \\
\hline Mean & SE \\
\hline 0.000 & 0.018 \\
\hline 0.408 & 0.028 \\
\hline 0.244 & 0.013 \\
\hline
\end{tabular}

CHC, high-carbohydrate diet $(890 \mathrm{~g}$ sucrose $/ \mathrm{kg}) ; \mathrm{PRO}$, carbohydrate-free high-protein diet $(890 \mathrm{~g}$ casein $/ \mathrm{kg}$ ); CHO-PRO, mixed carbohydrate-protein diet ( $500 \mathrm{~g}$ sucrose $+390 \mathrm{~g}$ casein $/ \mathrm{kg}$ ); for details of composition of diet, see p. 444 .

* Mucosal weight of PRO $>\mathrm{CHO}(P<0.05)$.

regardless of carbohydrate content (Lifshitz et al. 1972). The finding that hexose absorption is enhanced when protein content is low regardless of carbohydrate content (in the range fed) suggests protein may suppress hexose absorption. Feeding $650 \mathrm{~g}$ sucrose $/ \mathrm{kg}$ in a semi-synthetic diet enhanced hexose absorption in comparison with commercial laboratory chow which contains approximately $500 \mathrm{~g}$ complex carbohydrates $/ \mathrm{kg}$ (Reiser et al. 1975). These results are similar to our findings with natural food and semi-synthetic diets.

In view of the increase in hexose specific absorption with carbohydrate content of diets (Fig. 3), the lack of effect of protein content of diet on L-leucine specific and total absorption is of interest (Table 2). Previous in vivo studies on responses of amino acid absorption to dietary stimuli have shown increased (Lis et al. 1972), and decreased (Adibi \& Allen, 1970) absorption. Although the present and previous studies cannot be compared directly, hexose and amino acid appear to respond differently to the various stimuli. In our experiments, under identical dietary composition, hexose and amino acid absorption responded differently.

When a second stimulus, energy restriction, was combined with that of variation in dietary composition, the body-weight losses were more pronounced: $\mathrm{CHO} 19 \%$, $\mathrm{CHO}$ PRO $13 \%$, and PRO $12 \%$. Restriction of the $\mathrm{CHO}$ diet to $118 \mathrm{~kJ} / \mathrm{d}$ did not result in a reduction of mucosal mass compared to the $\mathrm{CHO}$ group taking $210 \mathrm{~kJ} / \mathrm{d}$ (Fig. 2), suggesting maintenance of mucosal mass at the expense of other body tissues. Restriction of the two protein-containing diets resulted in a $29 \%$ reduction in mucosal mass compared to the group receiving $210 \mathrm{~kJ} / \mathrm{d}$. When the stimulus of energy restriction was added to that of dietary composition, hexose specific absorption was the same for all dietary groups (Fig. 3). Total absorption was also the same for all dietary groups (Fig. 6). Results from feeding diets at 210 and $\mathrm{I} 18 \mathrm{~kJ} / \mathrm{d}$ suggested that $(a)$ at a higher level of intake, hexose absorption depends on dietary composition; $(b)$ dietary restriction increases hexose absorption when not already stimulated by carbohydrate or depressed by protein in diet; and $(c)$ since dietary restriction does not further enhance absorption over the level of rats given $\mathrm{CHO}$ at $210 \mathrm{~kJ} / \mathrm{d}$, the stimuli of dietary composition and dietary restriction are not additive (assuming CHO stimulates absorption).

In vivo studies of effects of restriction of food intake have been interpreted as showing increased hexose absorption (Kershaw et al. 1960; Esposito, 1967; Levinson \& Englert, 1972; Sanford \& Smyth, 1974), no effect (Esposito, 1967), or a decrease (Levin et al. 1965; Levin, 1970). Fasting used as the energy restriction stimulus caused increased (Levinson \& 
Englert, 1972; Sanford \& Smyth, 1974) as well as decreased hexose absorption (Levin et al. 1965; Levin, 1970). Our studies showing enhancement of hexose absorption by energy restriction are in accord with many of the previous studies.

The hexose absorption stimulus of energy restriction appears to be more complex than originally envisioned. Previous studies examined restriction by reduced intake or fasting of a mixed carbohydrate-protein diet, and compared findings with controls receiving the mixed diet ad lib. Hence, effects could be attributed to reduction of intake. Our studies, however, show that effects of energy restriction on hexose transport depend in part on dietary composition. Specific (Fig. 3) and total (Fig. 6) transport did not change with restriction of the carbohydrate diet under conditions of our study. Restriction of the two protein-containing diets increased specific hexose transport (Fig. 3) in agreement with previous studies. The reason for failure of the carbohydrate diet to increase transport further when restricted is not clear. Assuming that both the carbohydrate diet and restriction are stimulatory to absorption, the failure of the combination to show an additive effect could be explained if both were the same stimulus, i.e. activating maximally the same pathways or mechanisms for enhancing absorption. Alternatively, two non-additive stimuli are acting. It is unlikely that supplying energy as carbohydrate provides the same stimulus as restricting the diet. Feeding carbohydrate would be expected to reduce the mobilization of endogenous protein and fat caused by energy restriction. If one hypothesizes that protein suppresses hexose absorption, then dietary restriction overcomes suppression and returns absorption to the uninhibited level.

The stimulus of diabetes combined with that of dietary composition was examined by comparing the response of diabetic and matched-control groups pair-fed the same diets (feeding period duration 2-3 d, duration of diabetes 3-4 d). Specific and total intestinal hexose absorption was independent of diet in diabetics and diet-dependent in controls (Figs. 5 and 6). Specific and total absorption were greater in diabetics than in controls for the PRO group, but did not differ significantly in the other two dietary groups, although significance level was approached in the CHO-PRO group $(P=0.05)$. Thus, when the stimulus of diabetes was combined with that of dietary composition, hexose absorption in the group transporting maximally (CHO) did not increase further.

Previous studies of effects of diabetes on hexose absorption are in accord with the present studies in demonstrating increased absorption in diabetic as compared with control animals (Flores \& Schedl, 1968; Levinson \& Englert, 1972; Schedl \& Wilson, 1971a). Effects of diet composition on hexose absorption in diabetes have not been examined previously.

Diabetes and energy restriction produced identical responses in hexose specific absorption (Figs. 3 and 5) and total absorption (Fig. 6), although diabetic rats consumed $210 \mathrm{~kJ} / \mathrm{d}$ and energy-restricted rats $118 \mathrm{~kJ} / \mathrm{d}$. Energy balance, however, is similar in the two groups, because diabetic rats excrete $5 \mathrm{~g}$ glucose $/ \mathrm{d}(84 \mathrm{~kJ})$ in urine at this stage of diabetes. In diabetes, since the food is eaten, it can exert direct effects on the alimentary tract as well as indirect effects from energy deficiency, whereas in energy restriction the food is withheld, and effects must be indirect. Diabetes and starvation produce similar effects on enzyme activities in the liver of rats, both states causing a reduction of enzymes below levels in the control state (Tyrrell \& Anderson, 1971). However, when enzyme levels of jejunal mucosa from the same groups of rats were examined, alloxan diabetes was associated with increased enzyme activities, while fasting reduced the activities. Hence the similarity in absorptive response of intestine in both diabetes and starvation is of interest.

The present studies indicate the scope and limitation of intestinal adaptive responses. Responsiveness of the intestine to the commonly encountered, clinically-important stimuli of dietary composition, energy restriction and diabetes suggest that these effects may be 
widespread and of importance to human health. The findings point the way for further studies examining the mechanisms of regulation and of the absorption process.

James D. Leeper, Biostatistics, University of Iowa, assisted in data analysis, Dr T. A. Anderson, Dep rtment of Pediatrics, advised on preparation of diets, and William D. Savage provided technical assistance.

\section{REFERENCES}

Adibi, S. A. \& Allen, E. R. (1970), Gastroenterology 59, 404. Bernhart, F. W. \& Tomarelli, R. M. (1966). J. Nutr. 89, 495.

Bray, G. A. (1960). Analyt. Biochem. I, 279.

Esposito, G. (1967). Proc. Soc. exp. Biol. Med. 125, 452.

Flores, P. \& Schedl, H. P. (1968). Am. J. Physiol. 214, 725.

Huntsberger, D. V. \& Leaverton, P. E. (1970). Statistical Inference in the Biomedical Sciences. Boston: Allyn and Bacon Incorporated.

Kershaw, T. G., Neame, K. D. \& Wiseman, G. (1960). J. Physiol., Lond. 152, 182.

Levin, R. J. (1970). Life Sci. 9, 6I.

Levin, R. J., Newey, H. \& Smyth, D. H. (1965). J. Physiol., Lond. 177, 58.

Levinson, R. A. \& Englert, E. Jr. (1972). Experientia 28, 1039.

Lifshitz, F., Hawkins, R. L., Diaz-Bensussen, S. \& Wapnir, R. A. (1972). J. Nutr. 102, 1302.

Lis, M. T., Crampton, R. F. \& Matthews, D. M. (I972). Br. J. Nutr. 27, 159.

Olsen, W. A. \& Rosenberg, I. H. (1970). J. clin. Invest. 49, 96.

Reiser, S., Michaelis, O. E., Putney, J. \& Hallfrisch, J. (1975). J. Nutr. 105, 894.

Sanford, P. \& Smyth, D. H. (1974). J. Physiol., Lond. 239, 285.

Schedl, H. P. \& Clifton, J. A. (1961). Gastroenterology 4I, 491.

Schedl, H. P., Miller, D. L., Wilson, H. D. \& Flores, P. (1969), Am. J. Physiol. 216, 1131.

Schedl, H. P. \& Wilson, H. D. (1971 a). Am. J. Physiol. 220, 1739.

Schedl, H. P. \& Wilson, H. D. (1971 b). J. exp. Zool. 176(4), 487.

Somogyi, N. (1952). J. biol. Chem. 195, 19.

Tyrrell, J. B. \& Anderson, J. W. (1971). Endocrinology 89, 1178. 